\title{
Continuum of the United States military's traumatic brain injury care: adjusting to the changing battlefield
}

\author{
Rachel Lazarus, PhD, ${ }^{1,2}$ Katherine Helmick, MS, ${ }^{1}$ Saafan Malik, MD, ${ }^{1}$ Emma Gregory, PhD, ${ }^{1}$ \\ Yll Agimi, PhD, ${ }^{1,3}$ and Donald Marion, MD ${ }^{1,2}$ \\ 1Defense and Veterans Brain Injury Center, Silver Spring, Maryland; and ${ }^{2}$ General Dynamics Health Solutions, and ${ }^{3}$ Salient
CRGT, Fairfax, Virginia
}

Over the past 8 years, advances in the US Military Health System (MHS) have led to extensive changes in the way combat casualty care is provided to deployed service members with a traumatic brain injury (TBI). Changes include the application of cutting-edge Clinical Practice Guidelines, use of pioneering technologies, and advances in evacuation procedures. Compared with previous engagements, current operations occur on a much smaller scale, and more frequently in austere environments, such that effective medical support is increasingly challenging. In this paper, the authors describe key aspects of the current continuum of TBI care in the US military, from the point of injury through rehabilitation, with an emphasis on how emerging technologies and evidence-based Clinical Practice Guidelines assist MHS clinicians with providing the best clinical care possible in the changing battlefield.

https://thejns.org/doi/abs/10.3171/2018.9.FOCUS18396

KEYWORDS Military Health System; Department of Defense; traumatic brain injury; service member; levels of care

I N 2010, Neurosurgical Focus dedicated an entire issue to military neurotrauma. Since then, significant changes have been made to US Department of Defense (DoD) guidance for general trauma and neurotrauma care in the deployed environment. By 2014-2015, major combat operations in Afghanistan and Iraq concluded. Subsequent combat operations have been on a much smaller scale, often in austere environments. In some cases, this has meant distances of several hundred miles to the nearest military medical facility. Consequently, there is a growing need for improved delivery of prolonged acute care at the point of injury. A key focus of the DoD Center of Excellence for Trauma (the Joint Trauma System [JTS] and its Committee on Surgical Combat Casualty Care [CoSCCC]) and the DoD Center of Excellence for Traumatic Brain Injury (the Defense and Veterans Brain Injury Center [DVBIC]) is to ensure optimal preparation and training of clinical providers for the acute and postacute care of service members deployed to austere combat locations. Improved preparation and training have been facilitated by the National Defense
Authorization Act of 2017 (NDAA; sections 706-708), ${ }^{13}$ which mandated extensive trauma exposure for active duty general surgeons prior to deployment. Because there are limited neurosurgical assets to support all deployed missions, a recent JTS Clinical Practice Guideline (CPG), Emergency Life-Saving Cranial Procedures by Non-Neurosurgeons in Deployed Setting, was developed in order to provide guidance for general surgeons to perform cranial surgery in cases in which a neurosurgeon is not available. ${ }^{1}$ Moreover, new guidance developed by the CoSCCC and DVBIC regarding trauma and traumatic brain injury (TBI) care is now more efficiently and rapidly disseminated throughout the DoD, most often in the form of CPGs or other related documents. Beyond development and dissemination of updated clinical guidance, the Military Health System (MHS) has improved far-forward field care by employing novel technologies for injuries, including TBI and polytrauma. Finally, substantial organizational optimization of the MHS is currently underway. The 2017 NDAA mandated the consolidation of the military treatment fa-

ABBREVIATIONS CoSCCC $=$ Committee on Surgical Combat Casualty Care; CPG = Clinical Practice Guideline; DoD = Department of Defense; DVBIC = Defense and Veterans Brain Injury Center; ICP = intracranial pressure; ISC = Intrepid Spirit Center; JTS = Joint Trauma System; MHS = Military Health System; MTF = military treatment facility; NDAA = National Defense Authorization Act; NICoE = National Intrepid Center of Excellence; OEF = Operation Enduring Freedom; OIF = Operation Iraqi Freedom; OND = Operation New Dawn; TBI = traumatic brain injury; VA = Veterans Affairs.

SUBMITTED August 1, 2018. ACCEPTED September 10, 2018.

INCLUDE WHEN CITING DOI: 10.3171/2018.9.FOCUS18396. 


\section{The five Levels of Combat Casualty Care following point of injury}

Level I: Battlefield aid
Immediate lifesaving measures and evacuation
- Immediate far-forward care. First-responder care and first-aid.
- Up to $70 \%$ of combat fatalities occur within first five minutes of injury
- Emphasis on controlling bleeding, stabilizing, and evacuating
- Combat medic, corpsman, and emergency medical technicians
- No surgical capability

\section{Level II: Forward surgical team and division-level} medical facilities

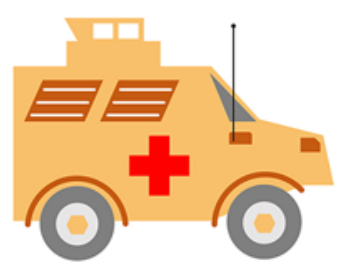

Assess and stabilize

- Highly mobile surgical team within combat zone, providing life-saving surgical care on-the-go

- Service Members who can be returned to duty within $24-72$ hours are held here for treatment

- Basic primary care and basic mental health support
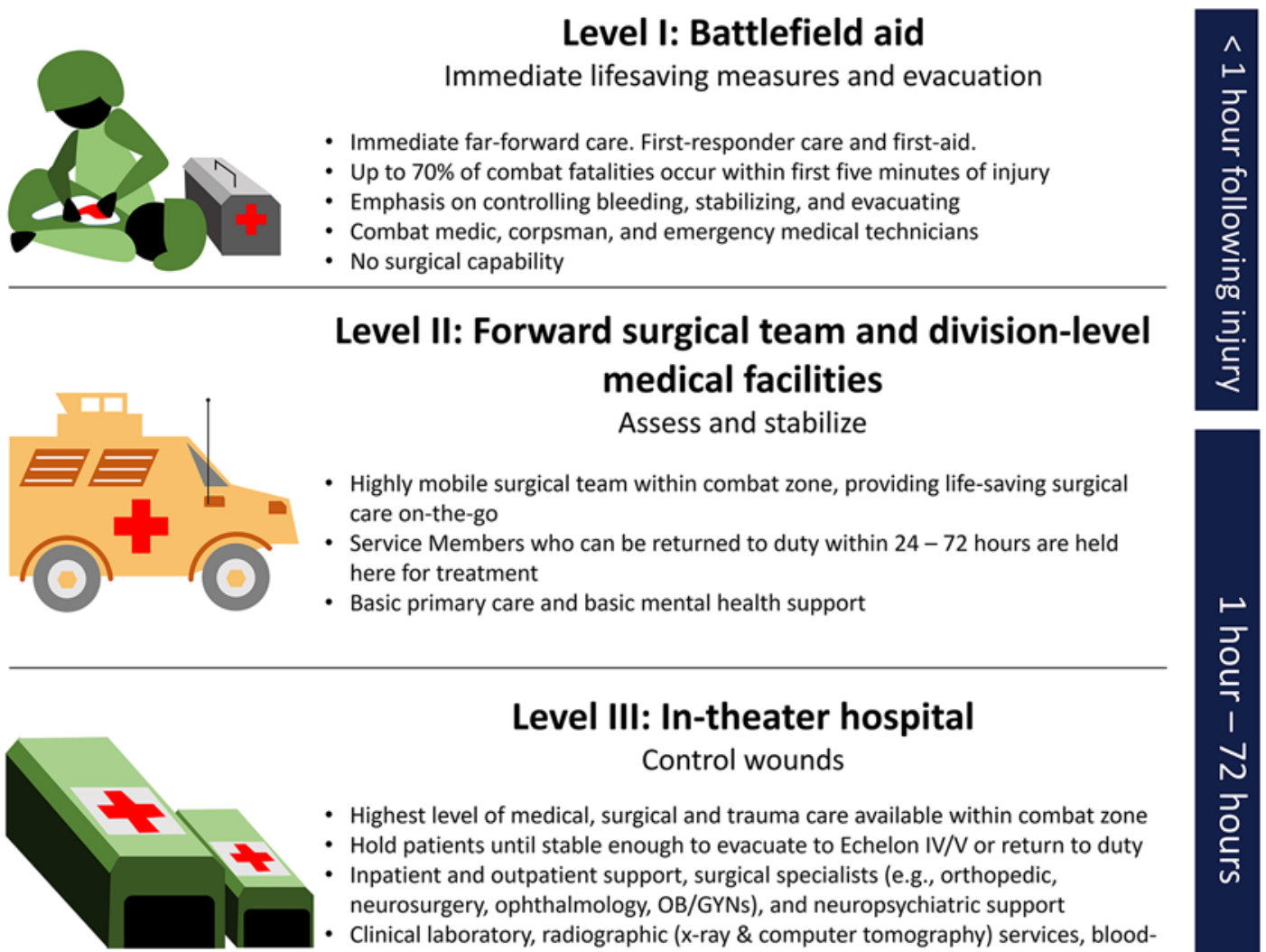

\section{Level III: In-theater hospital}

Control wounds

- Highest level of medical, surgical and trauma care available within combat zone

- Hold patients until stable enough to evacuate to Echelon IV/V or return to duty

- Inpatient and outpatient support, surgical specialists (e.g., orthopedic,

neurosurgery, ophthalmology, OB/GYNs), and neuropsychiatric support

- Clinical laboratory, radiographic (x-ray \& computer tomography) services, bloodbanking, and physical therapy

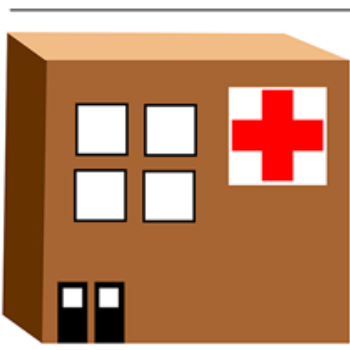

\section{Level IV: Non-theater Hospital} Optimize wounds

- Overseas military hospital (ex., Landstuhl Regional Medical Center)

- Permanent or semi-permanent facility outside of combat zone

- Surgical care, intensive care units, intermediate care wards, outpatient care, and intensive rehabilitation services

- If needed, stage of care to stabilize patient (usually no more than 72 hours) for evacuation to Echelon $\mathrm{V}$ (stateside)

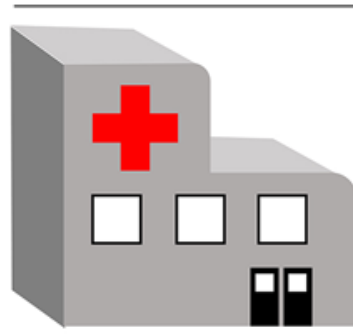

\section{Level V: US Military Hospital}

Definitive care

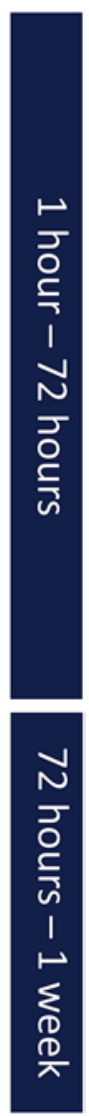

- Stateside base hospital

- The greatest capacity for treatment and rehabilitation: maximum quality of medical, surgical, and convalescent care for return to function.

- Ex.: Walter Reed National Military Medical Center, Naval Medical Center San Diego.

FIG. 1. There is a 5-tier (levels) structure of combat zone clinical care within the MHS. Progressive MHS levels denote differences in resources and capability, rather than the quality of care. Each level has the capability of the level forward of it, and expands on that capability. Service members with minor injuries can be returned to duty after basic care within the area of operations. All others are prepared for evacuation with medical care en route to a higher level.

cilities (MTFs) of the independent services under a single entity, the Defense Health Agency. This is anticipated to further enhance trauma care capability and efficiency.

In this report, we describe the 5-tier (levels) structure of combat zone clinical care within the MHS (Figs. 1 and 2), with special emphasis on recent developments intended to ensure the readiness of trauma surgeons with respect to TBI. Note that these levels in the MHS are distinct from the American College of Surgeons' use of the term in US trauma centers. Service members with minor injuries can be returned to duty after basic care, whereas all others are prepared for evacuation with medical care en route to a 


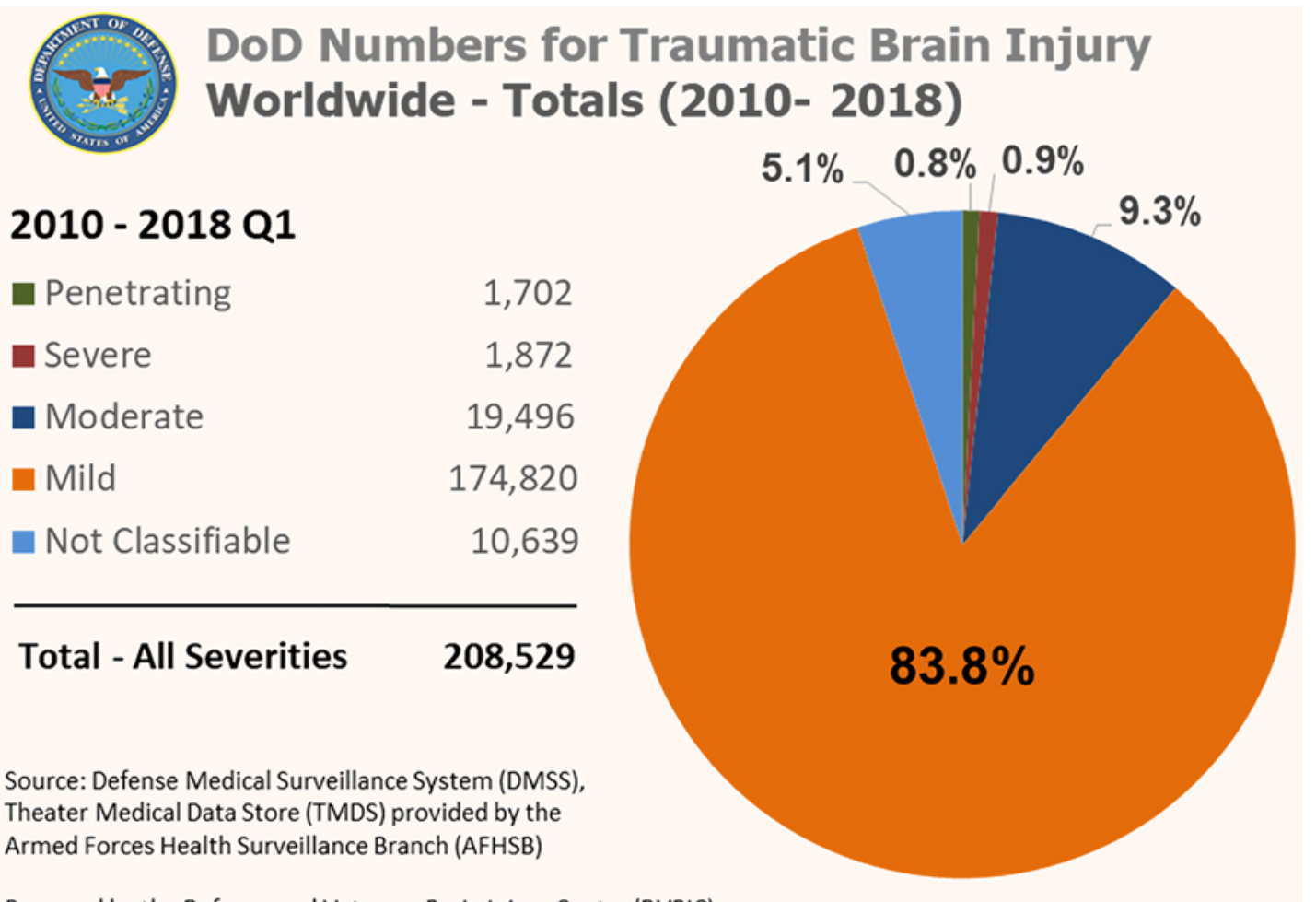

Prepared by the Defense and Veterans Brain Injury Center (DVBIC)

2010 - 2018 Q1, as of June 21, 2018

FIG. 2. The vast majority of TBIs sustained by service members between 2010 and 2018 were classified as mild TBI, also known as concussion. Percentages do not add to $100 \%$ due to rounding.

higher level of care. Progressive MHS levels denote differences in resources and capability, rather than the quality of care. Over the last decade, the definitions and capabilities of different levels have changed somewhat (e.g., level I corpsmen and combat medics must now be trained in Tactical Combat Casualty Care), but total manning at each level of care has not significantly changed.

\section{Readiness Prior to Deployment}

Military surgeons must be prepared for combat casualty care at all times. However, training opportunities can be limited: the San Antonio Military Medical Center is the only American College of Surgeons/Committee on Trauma-designated level I trauma center in the entire DoD. During Operations Enduring Freedom, Iraqi Freedom, and New Dawn (OEF, OIF, and OND, respectively), the vast majority of active duty general surgeons were not fellowship-trained trauma surgeons. In fact, frequently, these surgeons were recent graduates of civilian residency training programs that provided very little exposure to trauma. Concerns arose that general surgeons could be deployed to combat environments with insufficient expertise in combat casualty care.

In response, the 2017 NDAA (sections 706-708) called for trauma education and exposure for deploying general surgeons. ${ }^{13}$ Section 706 called for a military-civilian-integrated health delivery system through partnerships with health systems in the private sector to share medical resources, maintain operational medical readiness, and provide training opportunities. Section 708 required the establishment of a Joint Trauma Education and Training Directorate to ensure that traumatologists maintain readiness and are able to rapidly deploy. This directorate is empowered to enter into partnerships with civilian medical centers and teaching hospitals with level I civilian trauma centers. These partnerships allow military surgeons and physicians to embed within civilian trauma centers in order to ensure professional readiness. The 2017 NDAA, focused on general surgeons and other surgical specialties where trauma care (particularly neurotrauma care) may not have been included in residency training, has already had a significant impact: active duty military surgeons are now embedded in civilian level I trauma centers in states, including California, Missouri, and Maryland.

\section{Level I: Battlefield Care}

Level I care refers to the immediate first aid delivered at the time of injury. These life-saving measures are provided by oneself, buddy aid, or a combat lifesaver. ${ }^{7}$ The level I Battalion Aid Station (BAS) is often referred to as a "clearing station," and has no surgical capability. For those with life-threatening injuries, BAS capabilities include an initial assessment and immediate treatment of active hemorrhage and airway compromise.

Level I medical care typically available during combat operations may include a combat medic, independent duty corpsman, or unit physician. The Military Acute Concussion Evaluation (MACE) and the clinical management 
TABLE 1. FDA-cleared field-deployable devices or technology for the acute evaluation of TBI

\begin{tabular}{|c|c|c|c|c|}
\hline Device/Technology & Company & How Does It Work? & What Does It Show? & FDA Clearance \\
\hline BrainScope One & BrainScope & qEEG & Predicts abnormal CT results & 510(K) clearance: September 2016 \\
\hline Infrascanner & InfraScan & $\begin{array}{l}\text { Near-infrared spectros- } \\
\text { copy }\end{array}$ & $\begin{array}{l}\text { Intracranial hematomas } \geq 3 \mathrm{~cm}^{3} \text {, } \\
\quad<2 \mathrm{~cm} \text { from brain surface }\end{array}$ & 510(K) clearance: January 2013 \\
\hline $\begin{array}{l}\text { Lucid M1 Transcranial Doppler } \\
\text { Ultrasound System }\end{array}$ & $\begin{array}{l}\text { Neural Ana- } \\
\text { lytics }\end{array}$ & $\begin{array}{l}\text { Transcranial Doppler } \\
\text { ultrasonography }\end{array}$ & $\begin{array}{l}\text { CBF velocity: posttraumatic va- } \\
\text { sospasm, vascular occlusions }\end{array}$ & 510(K) clearance: November 2016 \\
\hline Brain Trauma Indicator & $\begin{array}{l}\text { Banyan Bio- } \\
\text { markers }\end{array}$ & $\begin{array}{l}\text { UCH L-1/GFAP blood test } \\
\text { (serum) via ELISA }\end{array}$ & Predicts abnormal CT results & $\begin{array}{l}\text { Breakthrough Devices Program (Expe- } \\
\text { dited Access Pathway): February } 2018\end{array}$ \\
\hline
\end{tabular}

$\mathrm{CBF}=$ cerebral blood flow; ELISA = enzyme-linked immunosorbent assay; $\mathrm{qEEG}=$ quantitative electroencephalography; $510(\mathrm{~K})=\mathrm{FDA}$ premarket notification.

This table of described devices is offered for informational purposes only. Their inclusion here does not constitute an endorsement or an approval by the Department of Defense of any of the products, services, or opinions of the external providers.

algorithm are often first implemented at level I care for any alert, awake service member suspected of having had a TBI. The MACE, similar to the Sport Concussion Assessment Tool (SCAT) used in sports medicine, includes tests of cognitive performance, neurological examination, and questions about symptoms. Importantly, the latest version of the MACE guides the provider to ask about clinical "red flags," symptoms, and/or signs of serious intracranial injury that may require neurosurgical intervention.

\section{Acute Medical Interventions}

Hemorrhage causes $85 \%$ of potentially preventable deaths after trauma. ${ }^{9}$ Hypotension associated with severe hemorrhage causes cerebral ischemia, and historically cerebral ischemia and hypoxia have been the primary causes for secondary brain injury following a severe TBI. ${ }^{12,14}$ Since 2003, senior military surgeons have recommended that every service member carry a tourniquet. During the last decade, several clamp-type devices have been introduced for the control of junctional hemorrhage (e.g., pelvic or shoulder) and are available for larger deployed units. ${ }^{10}$ Resuscitative endovascular balloon occlusion of the aorta (REBOA) has recently been introduced as a means for the temporary control of hemorrhage from intraabdominal injuries, and deploying surgeons have the opportunity for REBOA training. This intervention has been shown to effectively stabilize some casualties with severe liver or splanchnic hemorrhage, but it cannot be inflated for more than a few hours. ${ }^{11}$

Important lessons learned from OEF and OIF include the benefit of using whole blood rather than crystalloid for fluid resuscitation following hemorrhage. ${ }^{4}$ Unfortunately, during OEF and OIF, more than $90 \%$ of blood products shipped from the US military blood banks were not usable by the time they reached their destination because transport often took days or even weeks (J. Corley, presentation at Brooke Army Medical Center, 2018). As with past military conflicts, the "walking blood bank" remains an effective reserve of fresh blood and is increasingly utilized. ${ }^{5}$ Upon deployment, service members willing to give blood are screened so that blood in its whole form can be directly transfused from donor to patient. Fresh whole blood is superior to the blood components because it has better oxygen-carrying capability and better ability to restore normal clotting.
In the austere combat zone environment, control of the airway and restoration of normal ventilation is an additional challenge. A surgical tracheostomy is often the most expedient way to restore a patient's airway, especially if there have been massive facial injuries. Medics and corpsmen are trained to perform this procedure. Importantly, surgical tracheostomy avoids esophageal intubation, which is perhaps the most common complication associated with field intubation attempts. ${ }^{3}$

\section{Applicable Technology}

A variety of noninvasive, field-deployable techniques for the assessment of TBIs of all severities have emerged in the last 2 decades. Some of these techniques are now FDA cleared for clinical use. Examples of some of these devices are listed in Table 1.

Two of these devices (BrainScope One, BrainScope; and Infrascanner, InfraScan, Inc.) have been field tested at large military bases, are currently utilized in some deployed settings, and may be used more frequently in the near future. BrainScope One has been shown to identify with a very high level of sensitivity TBI patients likely to have abnormal findings on CT scanning. The Infrascanner device uses near-infrared spectroscopy to identify superficial intracranial lesions, such as subdural hematomas, with high sensitivity as long as the lesion is within $2 \mathrm{~cm}$ of the surface of the brain and is at least $3 \mathrm{ml}$ in volume. In this way, the Infrascanner has the potential to aid surgeons attempting to localize an intracranial mass lesion in theater when a CT scanner is not available. Analysis of blood-based biomarkers using a prototype benchtop device is currently under development, and initial testing and evaluation is expected to begin in early fiscal year 2019 at 3 MTFs. In addition, a point-of-care biomarker analysis device is being developed with plans for final clinical trials in late fiscal year 2019 .

\section{Field Management of Patients With Severe TBI}

Since 2005, JTS has published CPGs for the systematic management of severe TBI. CPG guidance recommends that initial trauma management first address life-threatening injuries and resuscitation. ${ }^{2}$ The best way to limit secondary brain injury is to restore normal blood pressure and tissue oxygenation. The CPG also recommends that blood products, particularly whole blood, be used rather 
than albumin or Hespan if colloids are needed. Maintenance of a systolic blood pressure of $\geq 110 \mathrm{~mm} \mathrm{Hg}$ is recommended. ${ }^{2}$ Normoventilation $\left(\mathrm{PaCO}_{2}\right.$ of $\left.35-40 \mathrm{~mm} \mathrm{Hg}\right)$ should be maintained. Prophylactic hyperventilation is not recommended, but may be used as a temporizing measure to reduce intracranial pressure (ICP) in the setting of suspected herniation.

Treatment of known or suspected intracranial hypertension remains a cornerstone of therapy in patients with severe brain injury. In contrast to civilian treatment, which relies heavily on mannitol for treatment of intracranial hypertension, the JTS CPG recommends the use of 3\% hypertonic saline (HTS). Although no randomized clinical trial has demonstrated that HTS is superior to mannitol for the treatment of intracranial hypertension, there are at least 2 battlefield-specific reasons for its use over mannitol. First, mannitol has a relatively short shelf life and crystallizes in hot weather conditions, such as those seen in the austere combat zones of OEF, OIF, and OND; once crystallized, mannitol cannot be safely reconstituted. Second, combat casualty situations often involve hemorrhagic shock, so mannitol, an osmotic diuretic, would be contraindicated, whereas HTS has been shown to be effective for volume resuscitation.

\section{Level II: Mobile Facilities for Assessment and Stabilization}

Level II care has increased medical capability and is the first level of care with any holding capacity for patients. It includes basic primary care, very limited surgical capabilities, and limited radiography capability. Level II medical care is provided by forward support medical companies and forward surgical teams, and is $100 \%$ mobile. One or more surgeons (although not specialty surgeons) are available to perform life-saving abdominal, chest, or extremity surgical care. Overall, level II medical teams have more advanced capabilities than level I teams, and typically have some minimal laboratory capabilities. These assets may be augmented on the basis of the tactical situation, mission, and location.

\section{Acute Medical Interventions Including Craniotomies}

This is the first level where general surgeons can practically consider performing a life-saving craniotomy for service members with enlarging intracranial hematomas. Currently, neurosurgical training is not standard for the majority of general surgeons, and a rotation on neurosurgery has been dropped from the requirements of the American Board of Surgery for board certification. Such lack of experience with craniotomy is a concern, as the number of active duty general surgeons far exceeds the number of active duty neurosurgeons, yet deployed general surgeons will likely receive patients with surgical intracranial injuries, particularly in austere battle locations.

Acknowledging these concerns, in 2017 a group of military and trauma neurosurgeons drafted the CPG Emergency Life-Saving Cranial Procedures by Non-Neurosurgeons in Deployed Setting. This CPG describes recommendations for the indications, training, equipment, and neurosurgical oversight of field craniotomies by nonneu- rosurgeons. ${ }^{1}$ The document was reviewed and approved by the American Association of Neurological Surgeons and the JTS CoSCCC. CPG training recommendations include 1) participation by active duty general surgeons in at least 10 cranial procedures supervised by a neurosurgeon prior to deployment; 2) exposure to at least one of these procedures within 1 year of deployment; and 3) completion of a cranial simulator course within 1 year of deployment. The single most important recommendation of this CPG is that there be real-time consultation with a neurosurgeon, preferably via video-teleconference, before the decision is made to perform a craniotomy.

\section{Level III: In-Theater Hospital}

Level III represents the highest level of medical care available within the combat zone. Level III is typically the first level of care with large inpatient capacity and an onsite neurosurgeon. In the Army, a level III facility is referred to as a Combat Support Hospital (CSH). The $\mathrm{CSH}$ is a fixed medical facility with several well-equipped operating rooms, presurgical prep areas, and ICU capabilities. General and specialized surgical capabilities (e.g., thoracic, dental, oromaxillofacial) are usually available. Advanced ancillary resources such as laboratory facilities, CT scanning, and blood banking are available.

Medical holding capabilities at level III facilities allow for patients with critical injuries or hemodynamic instability to be systematically resuscitated over the course of several days or weeks, if necessary. Transport from the level III to the level IV MTF, which typically is located several hundred miles outside the combat zone, may require a flight of at least 6 hours. Because inflight resuscitation can be very challenging, a patient at risk for acute hemodynamic or pulmonary decompensation usually is held for several days at the level III MTF.

\section{Aeromedical Transportation to Higher Level of Care: Infrastructure and Medical Considerations}

Once the patient is hemodynamically stabilized at the level III MTF, aeromedical evacuation to a level IV MTF is planned, if necessary. For those who are critically injured, including most service members with a severe TBI, the Air Force Critical Care Air Transport Team (CCATT) is deployed to conduct the transport. CCATT is a highly specialized medical asset that can create and operate a portable ICU onboard any available transport aircraft during flight. ${ }^{6}$ The CCAT is a 3-person medical team consisting of a physician (specializing in critical care, pulmonology, or surgery), a critical care nurse, and a respiratory care technician. A retrospective review of OEF and OIF CCATT records (2001-2010) demonstrated a historically low mortality rate associated with CCATT-aided evacuation to Landstuhl Regional Medical Center. ${ }^{8}$

The 2017 CPG Neurosurgery and Severe Head Injury describes considerations for the safe and effective transport of service members with severe TBI from level III to level IV facilities. ${ }^{2}$ ICP monitoring is recommended during aeromedical evacuation for all patients with a severe TBI who have a Glasgow Coma Scale score of 8 or less, who have abnormal CT scan results, and who are not 
considered moribund. Due to stresses of flight (including noise, hypoxia, and altitude), observation in theater may be warranted for patients with borderline or difficult to manage intracranial hypertension. ${ }^{2}$ Patients with ongoing resuscitative requirements and an intracranial lesion, or the potential for development of cerebral edema, may require delayed evacuation. If the service member has drains from a craniotomy or a ventriculostomy, these are not removed prior to aeromedical evacuation. If present, pneumocephalus is usually a contraindication to flight: the decrease in atmospheric pressure at high altitudes can lead to expansion of intracranial air. This may be less of a concern for those who have undergone a decompressive craniectomy prior to the evacuation flight.

\section{Level IV}

Level IV refers to definitive medical and surgical care outside of the combat zone, but within the communication zone of the theater of operations. Level IV MTFs are fullservice medical centers with all levels of subspecialty care, imaging capabilities, extensive laboratory capabilities, multiple operating rooms, ICUs and inpatient beds, and outpatient clinics. The next evacuation flight for an injured service member out of a level IV facility will be to a level $\mathrm{V}$ MTF in the continental US, requiring a transoceanic flight. For patients with severe TBI, transport to the level V MTF usually is not attempted until ICP has been stabilized. During OEF and OIF, the primary level IV MTF to which casualties were evacuated was Landstuhl Regional Medical Center in Germany. Since 2001, more than 95,000 service members from Afghanistan and Iraq have been evacuated to and treated at this medical center (http://rhce. amedd.army.mil/landstuhl/).

\section{Level V}

Service members who are medically stable but require acute care beyond 5-10 days are transferred to a stateside level V MTF. Level V MTFs are large, full-service medical centers in the continental US, such as Walter Reed National Military Medical Center (WRNMMC) and the San Antonio Military Medical Center. These facilities are designated by the DoD to provide maximum return of function through a combination of medical, surgical, rehabilitative, and convalescent care.

Service members with complicated mild to moderate TBI also are treated at WRNMMC and benefit from the National Intrepid Center of Excellence (NICoE). This state-of-the-art facility is housed on the WRNMMC campus in a building specially designed and staffed for the comprehensive evaluation and treatment of service members with persistent or complicated postconcussive symptoms. Cutting-edge diagnostic evaluation, treatment planning, outpatient clinical care, and world-class TBI and psychological health clinical research are conducted at the NICoE. The NICoE is closely aligned with a network of 9 Intrepid Spirit Centers (ISCs) across the nation. Each ISC serves to augment the effectiveness of TBI and psychological health clinical care provided at stateside bases, including Camp Lejeune, Fort Hood, Camp Pendleton, and Joint Base Lewis-McChord.

\section{Stateside Rehabilitation}

The Department of Veterans Affairs (VA) provides long-term medical care through the Veterans Integrated Service Networks (VISNs). There are 21 VISNs located in distinct geographic regions throughout the US. Each VISN includes a VA healthcare system, one or more VA medical centers, multiple outpatient clinics, community service programs, and community-based outpatient clinics. Five VA facilities provide intensive rehabilitative care for severe TBI, and are designated as polytrauma rehabilitation centers, in recognition of the fact that TBI in the military rarely occurs in isolation. The James A. Haley VA in Tampa, Florida (VISN 8), is one of the 5 VA facilities designed to provide intensive rehabilitative care for severe TBI and has become the leading rehabilitation program for service members with severe TBI and long-term rehabilitation needs.

\section{DVBIC: A Dynamic and Engaged TBI Center of Excellence}

Congressionally mandated in 1991, DVBIC's mission is to conduct military- and veteran-relevant TBI research that maps to identified DoD research gaps; leads the development of DoD TBI clinical standards of care for TBI; deploys clinical tools, practices, and programs to the field; and educates clinical providers throughout the system on emerging science and evidence-based care. Additionally, DVBIC is involved in influencing DoD policy that addresses TBI management and care throughout the MHS. Over the last 8 years, DVBIC has played a pivotal role in supporting the JTS's revisions of clinical standards addressing the management of severe and penetrating TBI. New findings are translated to actionable practice changes that are relevant and particular to the military battle space. Furthermore, DVBIC has a strong and long-standing collaboration with the NICoE, ISCs, and the VA polytrauma system of care.

\section{Conclusions}

Important lessons have been learned from OEF, OIF, and OND, as well as other active military engagements. At the same time, the landscape of combat casualty care is changing. Engagements in the immediate future may be smaller in scope across multiple austere and remote locations, and there will be a growing need for improved delivery of prolonged acute care at the point of injury. Welltrained, fully equipped forward surgical teams must be provisioned for chest, abdominal, and cranial procedures. Far-forward squads are unlikely to be accompanied by combat-deployed neurosurgeons. Active engagements may involve general surgeons performing life-saving cranial procedures; therefore, general surgeons will need more extensive neurosurgical training. Time must be set aside for general surgeons' exposure to cranial surgery during their predeployment trauma center experience. The development and fielding of new, noninvasive technology promises to significantly improve battlefield assessment of TBI, and help surgeons localize surgical intracranial mass lesions. Through fellowship, flexibility, and teamwork, civilian 
neurosurgeons can help ensure that active duty surgeons are fully prepared to deliver the finest care possible to our deployed service members.

\section{References}

1. Bell R, McCafferty R, Shackelford S, Tomlin J, Dirks M, Neal C, et al: Joint Trauma System Clinical Practice Guideline: Emergency Life-Saving Cranial Procedures by NonNeurosurgeons in Deployed Setting (CPG ID:68). Fort Sam Houston, TX: Department of Defense Center of Excellence for Trauma, 2018 (http://jts.amedd.army.mil/assets/docs/cpgs/ JTS_Clinical_Practice_Guidelines_(CPGs)/Emergency Cranial_Procedures_by_Non-Neurosurgeons_Deployed_ Setting_23_Apr_2018_ID68.pdf) [Accessed October 15, 2018]

2. Bell R, McCafferty R, Shackelford S, Tomlin J, Dirks M, Neal C, et al: Joint Trauma System Clinical Practice Guideline: Neurosurgery and Severe Head Injury (CPG ID:30). Fort Sam Houston, TX: Department of Defense Center of Excellence for Trauma, 2017 (http://jts.amedd.army. mil/assets/docs/cpgs/JTS_Clinical_Practice_Guidelines_ (CPGs)/Neurosurgery_Severe_Head_Injury_02_Mar_2017_ ID30.pdf) [Accessed October 15, 2018]

3. Bossers SM, Schwarte LA, Loer SA, Twisk JW, Boer C, Schober P: Experience in prehospital endotracheal intubation significantly influences mortality of patients with severe traumatic brain injury: a systematic review and meta-analysis. PLoS One 10:e0141034, 2015

4. Butler FK, Holcomb JB, Schreiber MA, Kotwal RS, Jenkins DA, Champion HR, et al: Fluid resuscitation for hemorrhagic shock in tactical combat casualty care: TCCC Guidelines Change 14-01--2 June 2014. J Spec Oper Med 14:13-38, 2014

5. Cap A, Beckett A, Benov A, Borgman M, Bryant B, Chen J, et al: Joint Trauma System Clinical Practice Guideline: Whole Blood Transfusion (CPG ID: 21). Fort Sam Houston, TX: Department of Defense Center of Excellence for Trauma, 2018 (https://rdcr.org/wp-content/uploads/2018/05/ Whole_Blood_Transfusion_15_May_2018_ID21.pdf) [Accessed October 15, 2018]

6. Critical Care Air Transport: Who we are. CCATT.info (http://www.ccatt.info/index.php/ccatt/ccatt-who-we-are) [Accessed October 15, 2018]

7. Cubano MA, Lenhart MK, Bailey JA, Costanzo GP, Eastridge BJ, Ficke JR, et al (eds): Emergency War Surgery. Fort Sam Houston, TX: Borden Institute, 2013
(http://www.cs.amedd.army.mil/FileDownloadpublic. aspx?docid=80035d1a-f208-473d-993b-6debfb17db91) $[$ Accessed October 15, 2018]

8. Ingalls N, Zonies D, Bailey JA, Martin KD, Iddins BO, Carlton PK, et al: A review of the first 10 years of critical care aeromedical transport during Operation Iraqi Freedom and Operation Enduring Freedom: the importance of evacuation timing. JAMA Surg 149:807-813, 2014

9. Kauvar DS, Lefering R, Wade CE: Impact of hemorrhage on trauma outcome: an overview of epidemiology, clinical presentations, and therapeutic considerations. J Trauma 60 (6 Suppl):S3-S11, 2006

10. Kotwal RS, Butler FK Jr: Junctional hemorrhage control for tactical combat casualty care. Wilderness Environ Med 28 (2S):S33-S38, 2017

11. Manley JD, Mitchell BJ, DuBose JJ, Rasmussen TE: A modern case series of resuscitative endovascular balloon occlusion of the aorta (REBOA) in an out-of-hospital, combat casualty care setting. J Spec Oper Med 17:1-8, 2017

12. Miller JD, Becker DP: Secondary insults to the injured brain. J R Coll Surg Edinb 27:292-298, 1982

13. National Defense Authorization for Fiscal Year 2017, Pub L 114-328

14. Young W: Secondary CNS injury. J Neurotrauma 5:219221, 1988

\section{Disclosures}

The authors report no conflict of interest concerning the materials or methods used in this study or the findings specified in this paper.

\section{Author Contributions}

Conception and design: Lazarus, Helmick, Gregory, Agimi, Marion. Analysis and interpretation of data: Lazarus, Malik, Gregory, Agimi, Marion. Drafting the article: Lazarus, Helmick, Malik, Gregory, Agimi, Marion. Critically revising the article: all authors. Reviewed submitted version of manuscript: all authors. Approved the final version of the manuscript on behalf of all authors: Lazarus. Administrative/technical/material support: Lazarus.

\section{Correspondence}

Rachel Lazarus: Research Division, Defense and Veterans Brain Injury Center, Silver Spring, MD. rachel.c.lazarus.ctr@mail.mil. 